\title{
Acidente botrópico fatal
}

\section{Death caused by bothrops poisoning}

Paula M. Luciano', Gyl Eanes Barros Silva², Marisa M. de Azevedo-Marques ${ }^{3}$

\begin{abstract}
RESUMO
Os acidentes ofídicos causados pelo gênero Bothrops ocasionam manifestações locais secundárias à ação inflamatória aguda do veneno. A ocorrência de óbito (em torno de 0,6\% do total de casos atendidos anualmente no Brasil) é rara, mas certamente, traumática. O relato deste caso visa chamar a atenção para possíveis complicações locais e sistêmicas (insuficiência renal e sepsis) neste tipo de envenenamento e enfatizar as medidas terapêuticas e de suporte que devem ser realizadas em tempo hábil.
\end{abstract}

Palavras-Chave: Mordeduras de Cobra. Bothrops. Envenenamento. Síndromes de Compartimento. Fasciotomia.

\section{Introdução}

No Brasil, os acidentes ofídicos são causados por serpentes dos gêneros: Bothrops (jararaca), Lachesis (surucucu), Crotalus (cascavél) e Micrurus (coral) ${ }^{1}$. Há predomínio dos acidentes causados pelo gênero Bothrops (correspondem a $85 \%$ das notificações encaminhadas ao Ministério da Saúde). Ocorrem mais no sexo masculino, em trabalhadores rurais, na faixa etária de 15 a 49 anos e nos membros inferiores ${ }^{1}$. Os envenenamentos acontecem periodicamente, com picos de incidência no começo e no final do ano. São notificados em torno de 20.000 acidentes e mais de 100 mortes por ano em todo país ${ }^{2}$. A mortalidade relaciona-se com o gênero de serpente responsável pelo acidente e ocorre principalmente nos acidentes causados pelo gênero crotalus $(60,5 \%)$, geralmente quando há demora no atendimento inicial (mais que 6 horas).

O quadro clínico e os dados de exames complementares dos acidentados devem-se às três principais atividades do veneno botrópico ${ }^{3}$ :

\section{Atividade Inflamatória Aguda}

Tem importância fundamental na caracterização clínica do acidente, sendo causada por frações bioquimicamente heterogêneas. Determina atividade inflamatória aguda e causa alterações no local e nas proximidades da picada. É importante destacar a dor e o edema local ou regional e a possível evolução com a formação de bolhas e necrose de partes moles.

\section{Atividade Coagulante}

É a fração do veneno tipo trombina, capaz de ativar os fatores da coagulação sanguínea. Leva ao consumo de fibrinogênio e formação de fibrina intravascular. Além dessa ação, também existem outras substâncias capazes de ativar a protrombina e o fator X, atuando também sobre a agregação e aglutinação plaquetárias. Pode tornar o sangue incoagulável.

\section{Atividade Hemorrágica}

Deve-se principalmente às hemorraginas do veneno. Rompendo a integridade do endotélio vascular podem levar a sangramentos em diversos locais.
1. Pós-graduanda do Departamento de Clínica Médica. Faculdade de Medicina de Ribeirão Preto - USP.

2. Pós-graduando do Departamento de Patologia. Faculdade de Medicina de Ribeirão Preto - USP.

3. Docente. Divisão de Emergência, Departamento de Clínica Médica. Faculdade de Medicina de Ribeirão Preto - USP.
Correspondência:

Unidade de Emergência - HCRP-USP

Rua Bernardino de Campos, 1000. 14015-030, Ribeirão Preto - São Paulo - Brasil

Artigo recebido em 22/10/2008 Aprovado para publicação em 06/03/2009 
O quadro clínico varia de acordo com a quantidade de veneno inoculada. Ocorrem desde sangramentos clinicamente evidentes, até alterações na coagulação, detectáveis apenas com a realização de exames complementares. As complicações locais mais graves e temíveis são necroses extensas, síndrome de compartimento e gangrena. São raras as complicações sistêmicas como hipotensão arterial e choque devido à liberação de bradicinina e/ou serotonina pelas enzimas do veneno.

A insuficiência renal não é comum nos atendimentos realizados nas primeiras 6 horas. Quando existe, é de origem multifatorial: vômitos frequentes e perdas para o terceiro espaço podem levar à desidratação e a estado de choque. Há também a possibilidade de formação de microtrombos nos capilares renais e de ação nefrotóxica do veneno ${ }^{3}$.

\section{Relato do Caso}

Paciente do sexo masculino, 59 anos, branco, lavrador, encaminhado a Unidade de Emergência do HCFMRP-USP devido a "picada de cobra" na face anterior da perna direita há 2 horas e meia. Apresentava dor local intensa, náuseas e vômitos. Negava exteriorização de sangramentos. Negava afecções prévias e/ou uso de medicamentos.

Ao exame físico, encontrava-se em bom estado geral, eupnêico, corado, hidratado, afebril, anictérico e acianótico. Apresentava pressão arterial (PA) de 140 x 70mmHg, frequência cardíaca (FC) de 108 batimentos por minuto (bpm), frequência respiratória (FR) de 28 incursões respiratórias por minuto (irpm) e temperatura axilar (Tax) de $36^{\circ}$ Celsius (C).

Destacavam-se no exame físico, os achados locais da picada, com a presença de edema, calor e petéquias no $1 / 3$ inferior da perna direita. A hipótese diagnóstica de acidente botrópico moderado foi proposta, seguindo a classificação da gravidade dos acidentes botrópicos apresentada no Quadro 1 .

O paciente foi previamente medicado por via endovenosa com ranitidina, maleato de dextroclorfeniramina e hidrocortisona com objetivo de diminuir possíveis reações de hipersensibilidade do tipo imediato, que podem ser ocasionadas pelos soros heterólogos $^{5}$. Recebeu 8 ampolas de soro anti-botrópico por via endovenosa, 30 minutos após. Foi hidratado e utilizados sintomáticos para alívio da dor. Colhidos exames, cujos resultados foram: hemograma completo, com hemoglobina $(\mathrm{Hb})$ de $16,4 \mathrm{~g} / \mathrm{dl}$, hematócrito $(\mathrm{Ht})$ de 49,0\%, contagem de leucócitos de 26.000, com 6\% de bastões, $90 \%$ de segmentados e $4 \%$ de linfócitos, plaquetas de 283.000; uréia de $36 \mathrm{mg} \%$ e creatinina de 1,4 mg\%; sódio de $142 \mathrm{mmol} / \mathrm{l}$ e potássio de 3,39 $\mathrm{mmol} / \mathrm{l}$; tempos de protrombina (TP) e de tromboplastina parcial ativada incoaguláveis; urina I com cilindros granulosos, proteína +++ , heme pigmento +++ e 80 - 100 hemácias por campo.

Cerca de 2 horas após a admissão hospitalar, houve progressão rápida do edema em membro inferior direito (MID), com acometimento de toda perna, até a região da patela, acompanhado de cianose. Devido aos achados locais muito evidentes, foram aplicadas mais 4 ampolas de soro anti-botrópico e reclassificou-se o acidente como grave. Neste momento foi solicitada avaliação da clínica ortopédica, que contraindicou de imediato, a realização de fasciotomia, baseando-se na aferição das pressões intra-compartimentais do MID, que mostravam uma pressão intracompartimental $20 \mathrm{mmHg}$ menor que a pressão arterial média que era de $120 \mathrm{mmHg}$. Após 8 horas da admissão, apresentou sinais de comprometimento

\section{Quadro 1}

Acidentes Botrópicos: classificação quanto à gravidade e soroterapia recomendada ${ }^{4}$ :

\begin{tabular}{llll}
\hline Manifestações & Leve & Moderada & Grave \\
\hline $\begin{array}{l}\text { Locais } \\
\text { (dor, edema, equimose) }\end{array}$ & Ausentes ou discretas & Evidentes & Intensas \\
$\begin{array}{l}\text { Sistêmicas } \\
\text { (hemorragia grave, choque e anúria) }\end{array}$ & Ausentes & Ausentes & Presentes \\
$\begin{array}{l}\text { Tempo de Coagulação (TC) } \\
\begin{array}{l}\text { Soroterapia } \\
\text { (n' } \text { de ampolas) }\end{array}\end{array}$ & $\begin{array}{c}2 \text { a } 4 \\
\text { (endovenoso) }\end{array}$ & $\begin{array}{c}\text { Normal ou alterado } 8 \\
\text { (endovenoso) }\end{array}$ & $\begin{array}{c}\text { Normal ou alterado } \\
\text { (endovenoso) }\end{array}$ \\
\hline
\end{tabular}


sistêmico, evoluindo com febre (Tax de $39,6^{\circ} \mathrm{C}$ ), taquicardia e piora importante das condições locais.

Aproximadamente 18 horas da chegada ao hospital, devido à piora importante do estado geral do paciente, foi realizada fasciotomia em MID, com a documentação de isquemia e necrose em compartimentos anterior e lateral da perna, com tecido subcutâneo infiltrado e cianótico em região posterior da perna e coxa. Apresentava odor compartimental fétido e no joelho direito havia derrame de $++/ 4+$.

Após a cirurgia, o paciente encontrava-se agitado, com dor intensa em MID, desidratado, descorado, com má perfusão periférica e extremidades frias. A PA era de 100 x 50mmHg e a FC de 107 bpm. O MID apresentava perfusão lentificada (maior que 3 segundos). A diurese de $24 \mathrm{~h}$ foi de $1000 \mathrm{ml}$ (0,5 ml/kg/hora), apesar da hidratação vigorosa. Evoluiu com sinais de instabilidade hemodinâmica. Com hipótese diagnóstica de sepsis devido a infecção secundária no local da picada, foi iniciado antibioticoterapia com cloranfenicol, após serem colhidas duas amostras de hemocultura.

Dentro de um período de 28 horas de atendimento, o paciente foi submetido a intubação orotraqueal e ventilação mecânica. Necessitou de suporte pressórico com noradrenalina endovenosa contínua. Devido maior comprometimento clínico, foi realizada amputação suprapatelar do MID. Havia extensa necrose muscular da perna, principalmente no compartimento anterior, gangrena na região lateral e medial da coxa e odor fétido da ferida operatória.

Permaneceu com instabilidade hemodinâmica no período de pós-operatório imediato e evoluiu rapidamente para parada cardiorrespiratória em assistolia. Realizadas manobras de ressuscitação cardiorrespiratória sem sucesso.

A região amputada do MID foi enviada para exame anatomo patológico, que evidenciou: rabdomionecrose e hemorragia da panturrilha principalmente em sóleo, necrose epidérmica associada a congestão e edema da derme e subcutâneo e congestão dos vasos proximais. Diagnóstico de fasceíte necrotizante por acidente botrópico (Figuras 1 e 2).
Nas hemoculturas (2 amostras) e na secreção da ferida cirúrgica houve crescimento de Morganella morganii sensível a aminoglicosídeos, sulfametoxazoltrimetropim, imipenem e ciprofloxacina, resistente a penicilinas e cefalosporinas.

Não foi testado o cloranfenicol.

\section{Discussão}

A UE do HCFMRP-USP é o hospital de referência ao atendimento das vítimas de acidentes ofídicos da Divisão Regional de Saúde do Estado de São Paulo XIII (DRS-XIII). O Centro de Controle de Intoxicações (CCI) deste hospital, informa que, no período de janeiro de 1995 a dezembro de 2007 foram hospitalizados

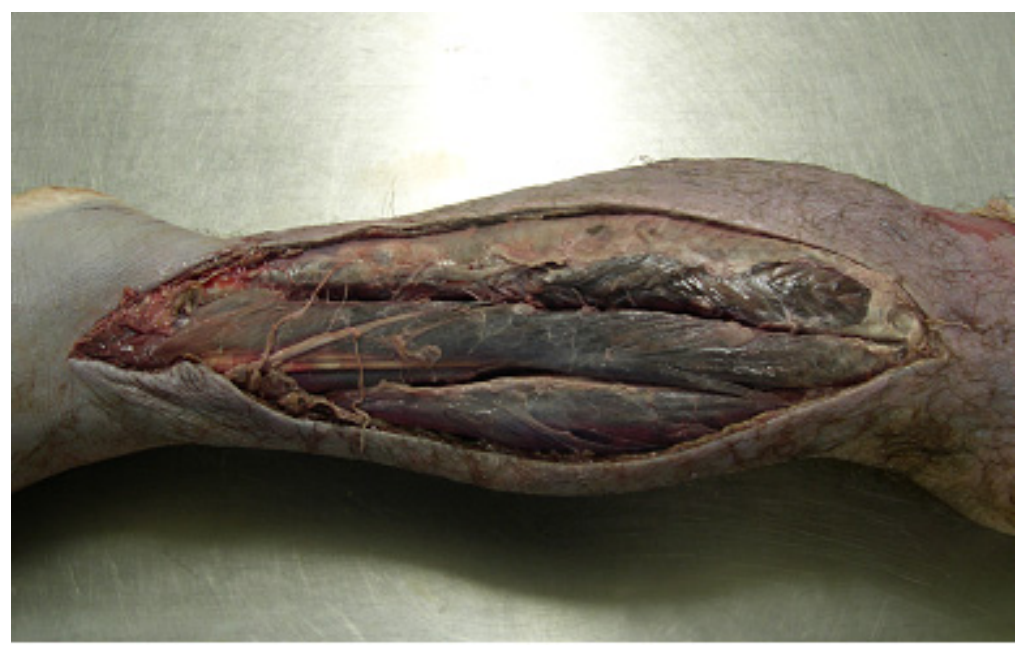

Figura 1: Face lateral da perna esquerda amputada com evidência de necrose extensa (fasceíte necrotizante).

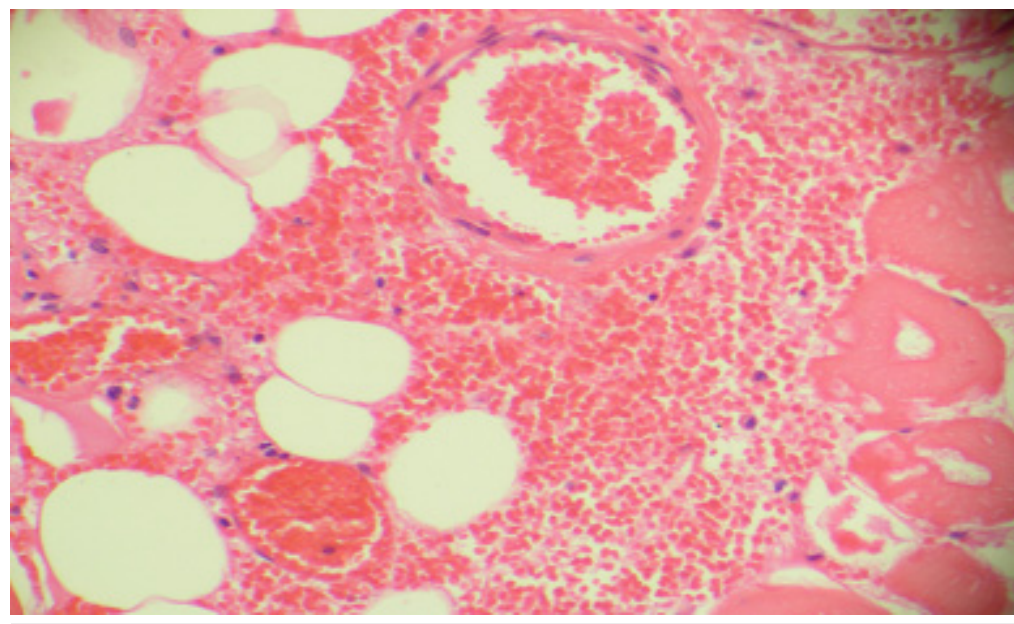

Figura 2: Achados microscópicos demonstrando hemorragia em musculatura da panturrilha, principalmente em sóleo. 
283 pacientes com idade acima de 18 anos, vítimas de acidente botrópico, com ocorrência de dois óbitos.

Durante o atendimento emergencial ao paciente foi cumprido o protocolo do CCI. Foi avaliada a gravidade do acidente ofídico e indicada soroterapia pertinente. A infusão do soro anti-veneno transcorreu sem intercorrências. O paciente permaneceu sob observação clínica com rápida evolução dos achados locais no MID, devido principalmente à ação inflamatória aguda do veneno. Sabe-se que esta ação depende da quantidade de veneno inoculado. A eficácia da ação anti-veneno do soro pode ser parcialmente avaliada pela normalização dos exames de coagulação dentro das primeiras 12 a 36 horas de atendimento. Como houve piora importante dos achados locais foram feitas mais 4 ampolas do soro anti-veneno. No entanto, quanto mais graves forem as lesões locais causadas pelo veneno, maior será a dificuldade para atuação do soro nessas áreas e a permanência do sangue incoagulável é que deve determinar a soroterapia adicional.

A síndrome compartimental é uma complicação local temível nos acidentes botrópicos podendo levar a sofrimento tecidual importante e repercussões sistêmicas catastróficas. Deve-se à compressão de feixe vásculo-nervoso consequente ao grande edema no membro acometido pela picada ${ }^{6}$. Quando presente, deve ser abordada precocemente levando-se em consideração principalmente os achados clínicos de déficit perfusional, como: dor intensa, parestesia, diminuição da temperatura do segmento distal, cianose e déficit motor. A aferição das pressões intra-compartimentais têm como regra geral o valor acima de $30 \mathrm{mmHg}$ da pressão diastólica como indicativo do procedimento de fasciotomia. No entanto, essa aferição não é rotineira e nem totalmente aceita, por isso, a indicação do procedimento cirúrgico deve basearse principalmente no julgamento clínico ${ }^{7 ; 8}$. O maior acometimento da vasculatura ocorre sobre as pequenas arteríolas que fornecem fluxo sanguíneo para os leitos capilares, e, os grandes vasos principais podem permanecer íntegros até uma fase mais avançada do processo. Assim, a conservação dos pulsos periféricos não reflete verdadeiramente a necrose isquêmica em prosseguimento. A dor à distensão é muito característica e consiste na incapacidade de realizar qualquer movimento do pé que distenda o músculo afetado sem provocar dor acentuada. A insuficiência renal aguda e a infecção secundária causada por bactérias gram negativas e anaeróbias são previstas. Como medida preventiva efetiva deve ser realizada fascio- tomia precoce, acompanhada de cuidados locais, desde que o estado da hemostasia do paciente permita. Também deve ser realizada hidratação vigorosa e iniciar antibiótico visando atuar sobre germes mais comumente encontrados em abscessos formados após picadas por cobras do gênero bothrops. Os germes mais encontrados são: morganella morganii, escherichia coli, providencia $s p$, streptococos do grupo D, enterobacter e bacteróides ${ }^{9}$.

$\mathrm{O}$ paciente evoluiu com quadro de sepsis grave, choque séptico refratário e óbito.

Os óbitos nos acidentes ofídicos podem estar relacionados a diversos fatores como: tamanho da serpente, quantidade de veneno inoculado, qualidade do atendimento prestado e a fatores desconhecidos próprios de cada vítima. A gravidade do acidente está relacionada com maior chance de óbito. Com o intuito de melhor avaliar a gravidade dos acidentes botrópicos foi realizado trabalho no Hospital Vital Brazil do Instituto Butatan - $\mathrm{SP}^{10}$, buscando sua associação com o grau de venenemia. Neste trabalho, foram estudados 137 pacientes (picados por serpentes do gênero Bothrops), atendidos com menos de 48 horas da picada, em um período de 2 anos. Foi constatada associação entre a gravidade, a venenemia pré-soroterapia e os níveis séricos de fibrinogênio. Através desse trabalho pode-se concluir que a determinação da venenemia no período pré-soroterapia contribui para o aprimoramento da avaliação inicial dos pacientes picados por serpentes do gênero Bothrops, podendo ser um preditor de gravidade ${ }^{10}$. No entanto, não é um procedimento realizado de rotina, devido em parte a relação custo $\mathrm{x}$ benefício não vantajosa.

\section{Conclusões}

A vítima de acidente botrópico deve receber tratamento em centro especializado que disponha de recursos para prover suporte adequado. Existem complicações previsíveis e possivelmente evitáveis desde que o tratamento correto seja realizado em tempo hábil.

Toda vez que houver indicação para realização de fasciotomias e amputações, estas não devem ser adiadas, sendo o julgamento clínico de suma importância nessa indicação.

O choque séptico pode determinar óbito em curtos intervalos de tempo se a causa-base, com possibilidade de tratamento cirúrgico, não for abordada precocemente. 


\section{ABSTRACT}

The Snakebite caused by Bothrops gender cause local events secondary to acute inflammatory action of the poison. The occurrence of death (about $0.6 \%$ of all cases occurred each year in Brazil) is rare, but certainly traumatic. The report of this case aims to draw attention to possible local and systemic complications (sepsis and renal failure) in this type of poisoning and emphasize the therapeutic and supportive measures that should be carried out in a timely fashion.

keywords: Snake Bites. Bothrops. Poisoning.Compartment Syndromes. Fasciotomy.

\section{Referências Bibliográficas}

1. Araújo FAA, Santalúcia M, Cabral RF. Epidemiologia dos acidentes por animais peçonhentos. In: João Luiz Costa Cardoso, editor. Animais Peçonhentos no Brasil: Biologia, Clínica e Terapêutica dos Acidentes. São Paulo: 2003: 6-12.

2. Andrade Filho A, Campolina D, Dias MB. Toxicologia na prática clínica. Belo Horizonte: 2001.

3. Azevedo-Marques MM, Cupo P, Hering SE. Acidentes por animais peçonhentos: serpentes peçonhentas. Medicina (Ribeirão Preto) 2003; 36: 480-9.

4. Ofidismo. In: Fundação Nacional de Saúde, editor. Manual de Diagnóstico e Tratamento de Acidentes por Animais Peçonhentos. Brasília: 2001: 25.

5. Acidentes por animais peçonhentos. In: Ministério da Saúde, editor. Guia de Vigilância Epidemiológica. Brasília: 2005: 106.

6. Kouyoumdjian JA, Polizelli C. [Snake bites by Bothrops moojeni: correlation of the clinical picture with the snake size]. Rev Inst Med Trop Sao Paulo 1989; 31(2): 84-90.
7. Matava MJ, Whitesides TE, Jr., Seiler JG, III, Hewan-Lowe K, Hutton WC. Determination of the compartment pressure threshold of muscle ischemia in a canine model. $\mathrm{J}$ Trauma 1994; 37(1):50-8.

8. Whitesides TE, Haney TC, Morimoto K, Harada H. Tissue pressure measurements as a determinant for the need of fasciotomy. Clin Orthop Relat Res 1975;(113):43-51.

9. Jorge MT, Ribeiro LA, da Silva ML, Kusano EJ, de Mendonca JS. Microbiological studies of abscesses complicating Bothrops snakebite in humans: a prospective study. Toxicon 1994; 32(6):743-8.

10. França FOS. Associação de venenemia e da gravidade em acidentes botrópicos, no momento da admissão no Hospital Vital Brazil, do Instituto Butantan, SP. Instituto Butantan, 1997. 